\title{
Beobachtungen über die gedoppelten Albuminfraktionen im Serum, im Gehirnliquor und im Harn einer neuen Familie
}

\author{
Von I. Tschankov \\ Biocbemisches Laboratorium am Institut fïr Neurologie und Psychiatrie (Direktor: Prof. G. Ganev), SofialBulgarien \\ (Eingegangen am 22. April 1969)

\begin{abstract}
Ein neuer Fall von Bisalbuminämie bei einem Mädchen mit Epilepsie wird beschrieben. Es werden gedoppelte Albuminfraktionen im Serum, Liquor und Harn des Kindes, sowie bei 15 der 36 untersuchten Verwandten nachgewiesen. Die eine der beobachteten Albuminfraktionen hat dieselbe elektrophoretische Beweglichkeit wie die Albuminfraktion des Normalserums und die zweite befindet sich zwischen der obigen und $\operatorname{der} \alpha_{1}$-Globulinfraktion.
\end{abstract}

\section{Observations on the doubled albumin fractions in the serum, cerebrospinal fuid and urine of a nen family}

The present work describes a new case of bis-albuminaemia in an epileptic girl. Doubled albumin fractions were demonstrated in the serum, cerebrospinal fluid and urine of the child and in 15 of the 36 investigated relatives. One of the albumin fractions has the same electrophoretic mobility as the albumin fraction of normal serum, while the second migrates between the latter and the $\alpha_{1}$-globulin fraction.

In den letzten Jahren wurden gleichzeitig mit den Veränderungen der Proteinkomponenten des Blutserums unter pathologischen Bedingungen auch manche genetischen Variationen der Proteine entdeckt. Zum ersten Mal beschrieb ScheurLen (1) 1955 eine Bisalbuminämie bei einer Patientin mit Diabetes im Präkoma und Koma. Später stellte KNEDEL (2) Bisalbuminämie bei 8 Mitgliedern zweier Familien fest und bewies damit den genetischen Charakter dieser Anomalie. WUHRMANN (3) untersuchte die übrigen Familienmitglieder, zu denen die Patientin von Scheurlen gezählt wurde und fand noch 3 Träger von Bisalbuminämie. Damit konnte nachgewiesen werden, daß es sich auch bei dieser Familie um eine vererbte Bisalbuminämie handelt. Bisher ist nur eine geringe $\mathrm{Zahl}$ von Familien von verschiedenen Verfassern beschrieben (1-14). Unsere Beobachtungen über eine große Familie.stellen einen Beitrag zu obigen Untersuchungen dar.

\section{Methodik und Ergebnisse}

Ende 1963 untersuchten wir den Gehirnliquor eines 8jährigen Mädchens mit Epilepsie. Die Ergebnisse aus den Untersuchungen mit den Routinemethoden wiesen keine pathologischen Veränderungen auf. Bei der elektrophoretischen Auftrennung des Gehirnliquors traten unerwartet zwei massive Fraktionen in der Albuminzone auf. Die Auftrennung wurde auf 1 proz. Agarosegel unter Anwendung eines Veronal Puffers ( $\mathrm{pH} 8,6)$ durch-
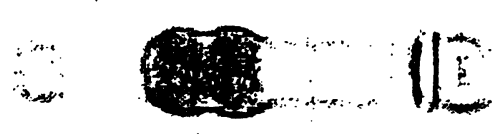

Abb. 1 Proteinelektropherogramm des Gehirnliquors mit Bisalbuminämie der geführt. Wir konzentrierten den Gehirnliquor in Dialysierschläuchen mit einer 50 proz. Lösung von Gummi arabicum.

Zehn Tage nach der Pneumoenzephalographie konnten wir abermals den Gehirnliquor sowie das Blutserum der Patientin untersuchen. Das Pherogramm beider biologischer Flüssigkeiten zeigten deutlich zwei parallel wandernde Albuminfraktionen. Dies gab uns den Anla $B$, ebenfalls den Harn der Patientin (auf dieselbe Weise wie oben konzentriert) $\mathrm{zu}$ untersuchen, wobei wir ein

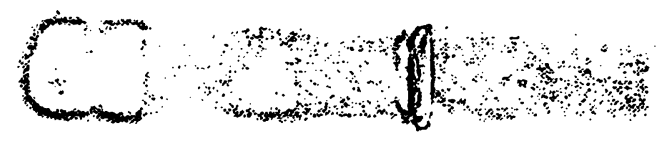

Abb. 2

Proteinelektropherogramm des Harns mit Bisalbuminämie

analoges Bild erhielten. Der konstante Charakter dieses überraschenden Befundes war der Beweis dafür, da $\beta$ es sich nicht um ein Artefakt handelt, sondern um eine allgemeine Proteinanomalie. Nunmehr mußte die Frage nach dem Charakter, der Herkunft und der Beziehung dieser Anomalie zur Erkrankung der Patientin beantwortet werden. Um einen Aufschluß darüber zu bekommen, trennten wir das Serum der Patientin parallel mit Normalserum auf. Es stellte sich heraus, daß die schneller wandernde Albuminfraktion eine gleiche Beweglichkeit wie die des Kontrollserums besitzt. Die langsamer wandernde Fraktion liegt zwischen der normal wandernden Albuminfraktion und "den $\alpha$-Globulinen im Proteinspektrum.

$\mathrm{Da}$ wir eine erbliche Anomalie vermuteten, untersuchten wir das Serum und den Harn vom Vater und Bruder der Patientin und erhielten analoge Bilder. Die erbliche Ubertragung der Bisalbuminämie in dieser Familie 


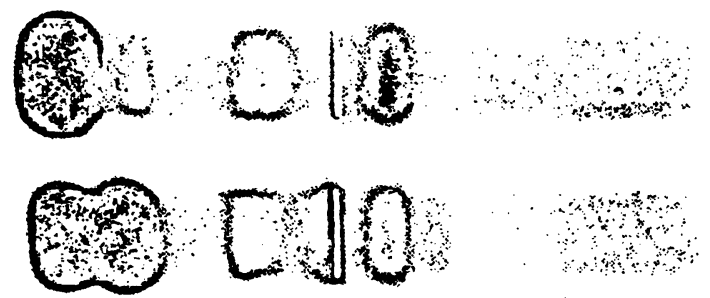

Abb. 3

Proteinelektropherogramm des Serums eines gesunden Probanden (oben) im Vergleich zum Serumproteinelektropherogramm der untersuchten Patientin (unten)

wurde hierduch zweifelsfrei erwiesen. Bei der Untersuchung von insgesamt 34 Verwandten dreier Generationen dieser Familie wurde bei 15 Bisalbuminämie festgestellt. Es wurden jedoch keine Krankheitssymptome beobachtet. Die gesamte Proteinmenge sowie die Menge des gesamten Albumins und das Verhältnis der Fraktionen bei allen Probanden mit Bisalbuminämie erwiesen sich als unverändert. Nur bei der Patientin mit Epilepsie konnte eine leichte Vermehrung der $\gamma$-Globuline bei gleichzeitiger Verminderung der Albumine festgestellt werden. Bèi allen Probanden mit Bisalbuminämie zeigte die langsam wandernde Albuminfraktion eine höhere Konzentration als die schnell wandernde Fraktion.

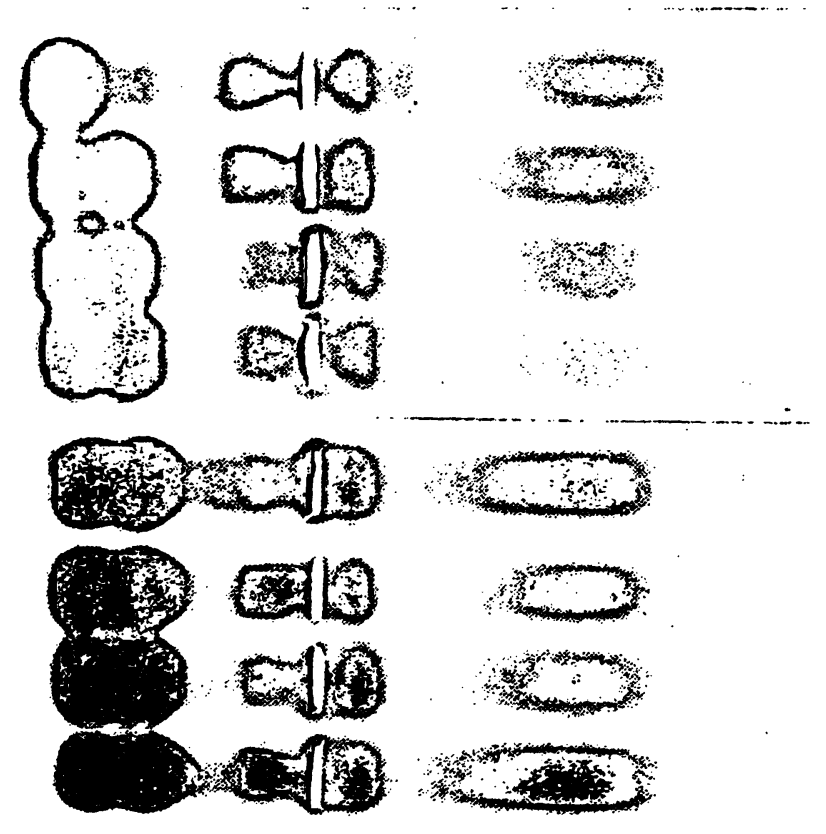

Abb. 4

Serumproteinelektropherogramm eines gesunden Probanden (oben) im Vergleich zum Serum einiger Familienmitglieder der beobachteten Patientin

\section{Diskussion}

Die Untersuchungsergebnisse über diese Familie mit Bisalbuminämie stellen einen weiteren Beitrag zu den bisherigen Beobachtungen der Proteinanomalie dar. Dabei beobachteten wir diese Anomalie gleichzeitig im Gehirnliquor, im Serum und im Harn. Gedoppelte Albuminfraktionen in den drei biologischen Flüssigkeiten wurden von Mrescher (10) und Bohrs (5) beschrieben. Die Anwesenheit von gedoppelten Albuminfraktionen in den drei biologischen Flüssigkeiten zeigt, $\mathrm{da} \beta$ in ihrer Proteinzusammensetzung ein gewisses Gleìchgewicht besteht. Wir müssen hier jedoch in Betracht ziehen, daß der Gehirnliquor auch einige spezifische Fraktionen enthält. Diese Tatsachen unterstützen den Standpunkt über die Herkunft der Proteine im Gehirnliquor, die teils im zentralen Nervensystem gebildet werden, teils aus dem Blut stammen sollen.

Die Vergleichsanalyse zeigte, daß bei dieser neuen Familie mit Bisalbuminämie die langsamer wandernde Albuminfraktion die zweite ist. Dieser Typus Bisalbuminämie konnte bisher bei dem überwiegenden Teil der bekannten Familien festgestsellt werden. Gleichzeitig beschrieb WIEME (14) einen anderen Typus, bei dem das abnorme Albumin vor einem normalen erscheint.

Über einen ähnlichen Fall berichteten TARNOKY und LESTAS (13), die gedoppelte Albuminfraktionen nur bei elektrophoretischer Auftrennung auf CelluloseAcetatfolie, nicht jedoch bei der Papierelektrophorese, auf Agarose- oder Stärkegel beobachteten. Offensichtlich sind die erblichen Proteinanomalien sehr verschieden und keine so große Seltenheit, für die man sie bisher gehalten hat.

Die genealogische Untersuchung bestätigte abermals die Vererbung der Bisalbuminämie. Die Hälfte der Angehörigen von drei Generationen dieser Familie erwiesen sich als Träger von gedoppelten Albuminfraktionen. Dabei verläuft die genetische Übertragung nach dominanter Reihenfolge. Erwies sich eine Person als Träger der Bisalbuminämie, so konnte diese bei sämtlichen Nachkommen nachgewiesen werden. Und umgekehrt - wenn sie bei einem Mitglied der Familie fehlte, so war sie bei dessen Nachkommen nicht nachweisbar. Das Auffinden der Bisalbuminämie bei Probanden verschiedenen Alters spricht dafür, daß sie das ganze Leben hindurch persistiert.

Das Vorhandensein einer zweiten Albuminfraktion führt nicht zum Anstieg des Gesamtproteins und Gesamtalbumins oder des Verhältnisses der Proteinfraktionen im Serum und im Gehirnliquor. Bemerkenswert
Abb. 5

Stammbaum der Familie. Die schwarzen Bezeichnungen bedeuten Träger der Bisalbuminämie

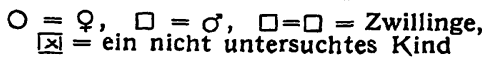

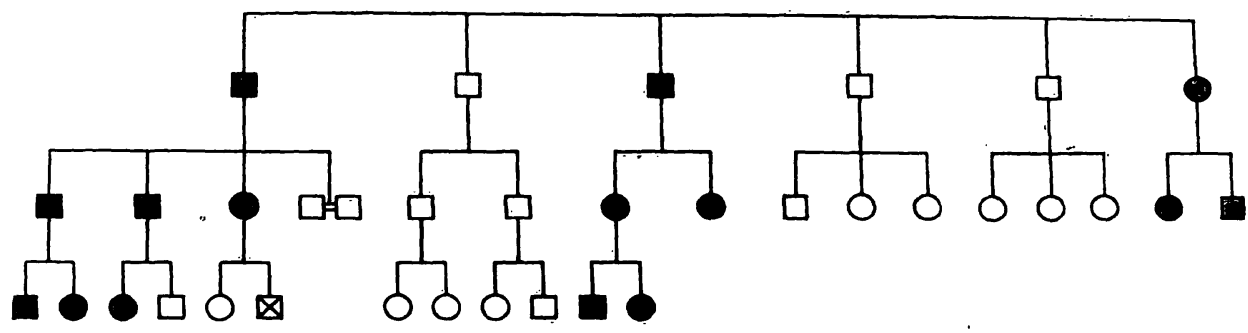

Z. klin. Chem. u. klin. Biöchem. / 9. Jahrg. 1971/ Heft 3 


\section{A \\ SUEMENS}

\section{Lล:borautomation}
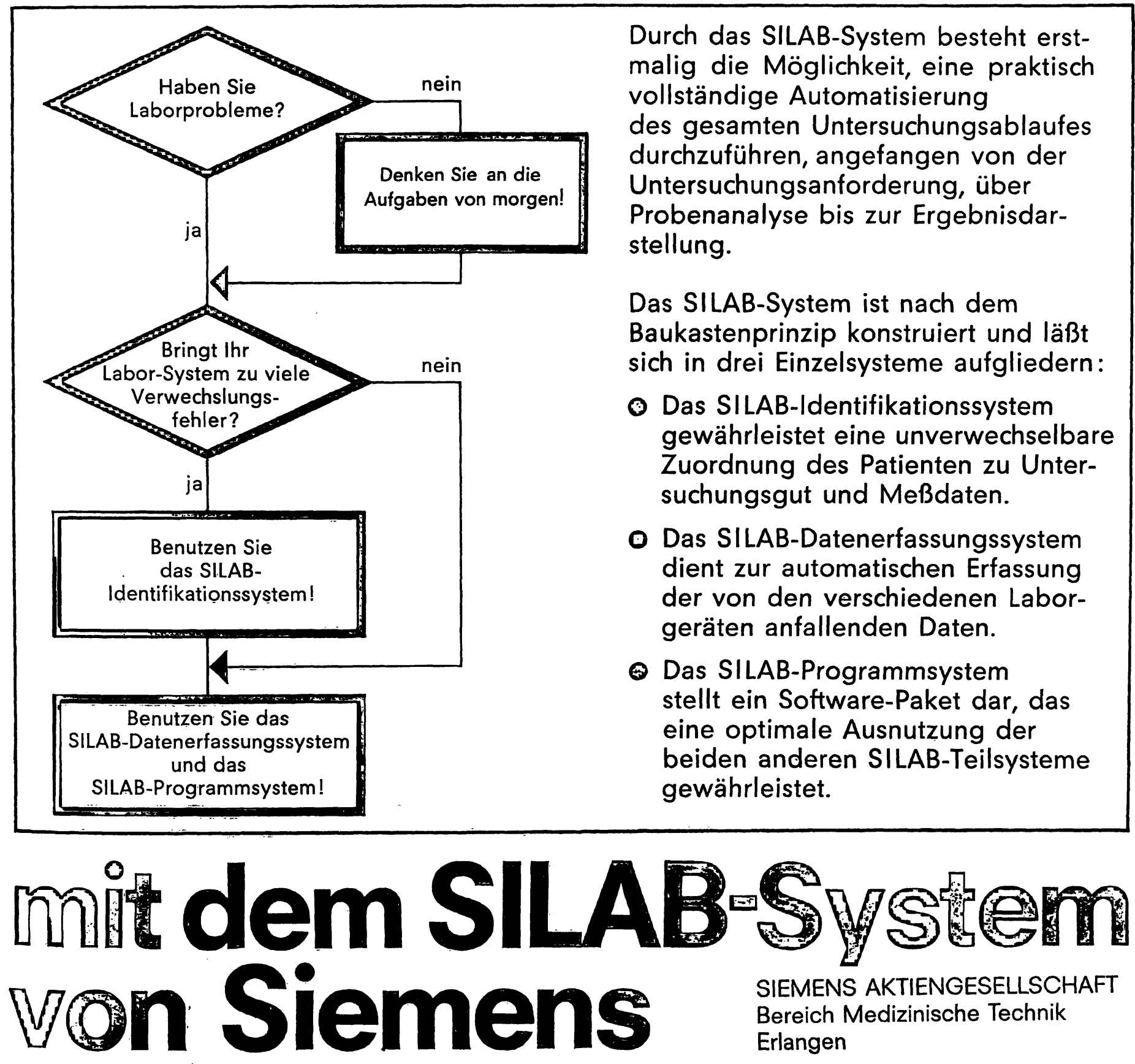


\section{NAD \\ Nicotinamid-Adenin-Dinucleotid \\ B-Diphosphopyridin-Nucleotid (DPN) \\ nicht abgepackt}

Verbraucher großer Mengen NAD sind eingeladen, ihren Bedarf mit Sigma zu diskutieren. Als ältester Hersteller des besten NAD und NADH der Welt sind wir vortrefflich in der Lage zur Kooperation. Mengen von vielen Kilogramm können unmittelbar von unserem umfangreichen Lager verfrachtet werden.

Preise: Können für unabgepackte Mengen sowohl für Auto-Analyzer- als auch Forschungsqualitäten vereinbart werden. Reinheit: Wir bieten verschiedene Reinheitsgrade an, um Ihrer Zufriedenheit żu genügen.

\section{Qualität V}

Diese ist ein in kleinen Partien nachgereinigtes NAD unserer bekannten Qualität III. Geringe Verunreinigungen wurden vermindert, um das "enzyme lag" zu eliminieren.

Literatur: 1. Dalziel, K., J. biol. Chemistry 238, 1538 (1963)

2. Winer, A. D., J. biol. Chemistry 239, PC 3598 (1964)

\section{Qualität III}

Unsere weltberühmie „Arbeitspferd"--Qualität: das vermutlich weltweit anerkannte NAD sowohl für Forschung als auch klinische Untersuchungen. Empfohlen, wo fast maximale Präzision wichtig ist.

\section{Qualität AA}

Eine spezielle Qualität, hergestellt für Anwendungen, die nicht die höchste Reinheit erfordern. Obwohl sie nicht unserer Qualität III entspricht, ist sie garantiert mindestens so rein wie jedes billigere NAD, das gegenwärtig für den Gebrauch in automatischen Analyzern zur Verfügung steht. Dennoch ist der Preis für unabgepackte Mengen von $100 \mathrm{~g}$ und mehr bedeutend geringer als er für unsere Qualität III möglich ist.

Wenn Sie einen wesentlichen Bedarf an NAD (DPN) haben, rufen Sie mich bitte zu jeder Tages- oder Nachtzeit und von überall her in der Welt "von Person zu Person" (selbstverständlich R-Gespräch) an. Ich denke, es könnte sich für Sie lohnen.

Danke

Dan Broida Mein Fernruf: 314-993-6418

St. Louis, Mo. USA

Es ist ein Vergnügen, Geschäfte mit Sigma zu machen Ich bin gewöhnlich erreichbar

Bestellen Sie direkt - R-Gespräch von überall her in der Welt

Tagsüber von Haus zu Haus, 314-771-5750 (auch Samstag und Sonntag bis 13.00 Uhr)

Wenn Sie mit Dan Broida persönlich sprechen möchten, rufen Sie „von Person zu Person“ 314-993-6418 Tag und Nacht.

Sigma-Reagenzien sind in der ganzen Welt durch den Fachhandel oder direkt aus St. Louis beziehbar.

Telegramme: SIGMACHEM, St. Louis, Missouri

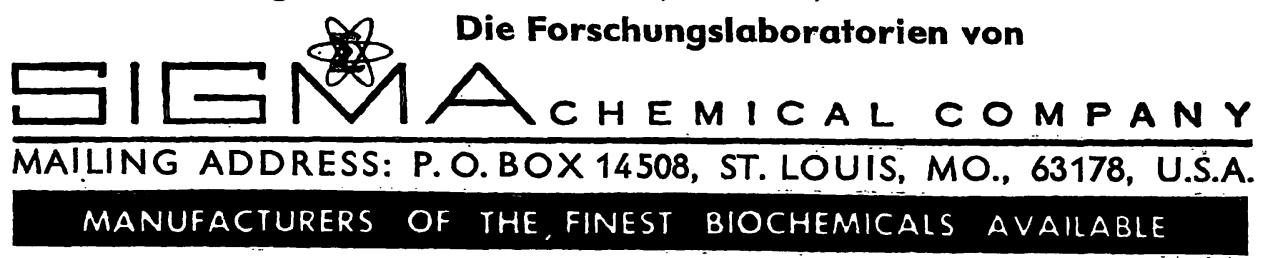

\section{Vertreten durch}

SIGMA LONDON Chem. Co. Ltd. - 12, Lettice St., London, S.W. 6., England Telephone: 01-736-5823 (Reverse Charges)

SIGMA ISRAEL Chem. Co. Ltd. 28 Kaf-Gimel St., Givataim, Israel Telephone: (03) 760654 (Reverse Charges) 
ist, daß das Verhältnis zwischen beiden Albuminkomponenten sehr konstant bleibt, wie auch von den Verfassern beobachtet wurde $(6,9,12)$. In sämtlichen Fällen hat das Albumin B eine höhere Konzentration als das Albumin A. Offensichtlich ist dies auf die erhöhte $\alpha_{1}$-Globulinkonzentration zurückzuführen. Wenn der Normalwert dieser Fraktion vom Albumin B abgezogen wird, so beträgt das Verhältnis der beiden Komponenten 1:1. Diese Tatsache wurde auch von SARCION beobachtet (12). Nach einigen immunchemischen Untersuchungen sind beide Albumine identisch. Andererseits stellte SARCION fest, daß sich das ${ }^{131}$ J-Thyroxin mit dem abnormen Albumin B verbindet und nicht mit Albumin A, das parallel mit dem Normalalbumin wandert. Eine unterschiedliche Affinität der beiden Albuminkomponenten gegenüber ${ }^{131} \mathrm{~J}$-Thyroxin stellten ebenfalls TARNOKY und LESTAS (12) bei dem „schnellen“" Typus Bisalbuminämie fest, wobei das schnellere
Albumin A eine größere Bindungsfähigkeit aufwies. Diese Tatsachen erwecken den Zweifel, daß die beiden Albumine nicht mit dem normalen identisch sind. Unabhängig von ihrem unterschiedlichen Verhalten im elektrischen Feld scheint es, daß beide Albuminkomponenten im Organismus die Funktion des normalen Albumins übernehmen. Ein Beweis dafür ist der gute gesundheitliche Befund sämtlicher Mitglieder der unsererseits untersuchten Familie. Der harmlose Charakter der Bisalbuminämie wird bei allen bisher beschriebenen familiären Fällen hervorgehoben, wenn sie auch bei Probanden mit Diabetes (1), Hepatitis (2), WEGNERscher Granulomatose (12), hereditärer Akrozyanose (9), Carcinom (13) und bei chronischem Alkoholismus (5) entdeckt worden ist.

Die Proteinanomalie unserer Patientin mit Epilepsie steht also in keinem Zusammenhang mit dieser Erkrankung.

\section{Literatur}

1. Scheurlen, P. G., Klin. Wschr. 33, 198 (1955). - 2. KNEDEL, M., Blut 3, 129 (1957), Clin. Chim. Acta, Amsterdam 3, 72 (1958).

3. WuhrmanN, F., Schweiz. med. Wschr. 89, 150 (1959). 4. Benhold, H., H. Otr und G. Scheurlen, Verh. Dtsch. Ges. inn. Med. 64, 279 (1959). - 5. Bohrs, S. W., F. Y. LarA, N. Thurmann und J. Keyes, Dis. nerv. Syst. 27, 727 (1966). 6. Earle, D. P., M. P. Hutr, K. Schmidt und D. Giltin, Trans. Ass. Amer. Physns 71, 69 (1958). - 7. EArLe, D. P., M. P. Hutr, K. Schmidt und D. Giltin, J. clin. Invest. 38, 1412 (1959). -
8. Giltin, G., K. Schmidt, D. P. Earle und H. Givelber, J. clin. Invest. 40, 820 (1961). - 9. Franglen, G., N. K. Martin, P. Hargreaves, M. J. Smith und D. J. Williams, Lancet, London 1960/I, 307. - 10. Mrescher, F., Schweiz. med. Wschr. 90, 1272 (1960). - 11. Nensteil, H. J. und T. Becht, Klin. Wschr. 35, 689 (1957). - 12. Sarcion, E. J. und C. W. Aungst, Blood 20, 2, 156 (1962). - 13. TARNoKY, A. L. und A. N. Lestas, Clin. Chim. Acta, Amsterdam 9, 551 (1964). - 14. Wreme, R. J., Clin. Chim. Acta, Amsterdam 5, 443 (1960).

Dr. I. Tschankov

Biochem. Laboratorium Inst. f. Neurologie u. Psychiatrie Sofia 13

Bulgarien 